\title{
Feynman Path Integral in Multiple-Slit and its Simulation
}

\author{
Mahendra Satria Hadiningrat ${ }^{1}$ \\ ${ }^{1}$ Department of Physics, Department of Science, Food Tech and Maritime, Institut Teknologi Kalimantan (ITK) \\ At. Sei Wain KM.15 Karang Joang, Balikpapan, East Kalimantan \\ E-mail: mahendra.itkbalikpapan@gmail.com
}

\begin{abstract}
In this article we hold on an analytic solution of the well-known cases of difraction and interference of electrons through one and two slits (simply that, the one-dimensional case is assumed only). In addition, we hold an approximations of the electron distribution which offer the interpretation of the results. Our derivation is based on the Feynman path integral formula and this work could also serve an awesome introduction to multiple slits interference. Then it is comparing between theoretical results and simulation in order to get interference pattern of it.
\end{abstract}

Keyword: Multiple-Slit Interference, Feynman Path Integral.

\section{Abstrak}

Pada artikel ini, terdapat pembahasan tentang solusi analitik dari kasus difraksi dan interferensi elektron yang dikenal dengan baik melalui satu dan dua celah (hanya saja, kasus satu dimensi merupakan asumsi). Sebagai tambahan, dibuatlah suatu perkiraan distribusi elektron yang menawarkan interpretasi hasilnya. Derivasi dibuat didasarkan pada rumus integral jalur Feynman dan dapat juga menyajikan pengantar yang mengagumkan untuk beberapa gangguan celah. Maka itu membandingkan antara hasil teoritis dan simulasi agar mendapat interferensi pola itu.

Kata Kunci: Interferensi Celah Banyak, Integral Lintas Feynman.

\section{Introduction}

In the early nineteen century, Thomas Young acted his well-known double-slit diffraction experiment using a light source, which gets the interference pattern on the screen. The interference effect is explained in detail by Huygens-Fresnel principle of classical optics theory. As a modern version of this experiment, the quantum double slit experiment are acted using photons, electrons, neutrons and so on. Necessarily using quantum mechanics in order to fathom the interference pattern for subatomic particles.

In standard quantum mechanics, the double-slit wave function is obtained as a special solution of the Schrodinger wave equation as the superposition of waves emitted from slits A, B at the points $(d / 2,0,0),(-d / 2,0,0)$

$$
F_{k}^{D S}(r, t)=F_{k}^{A}(r, t)+F_{k}^{B}(r, t)
$$

Where each solution is expressed by spherical waves as a good approximation in the region between slits and screen :

$$
\begin{aligned}
& F_{k}^{A}(r, t)=A_{0} \exp \left(-i \omega_{k} t+i k r_{A}\right) / r_{A} \\
& F_{k}^{B}(r, t)=B_{0} \exp \left(-i \omega_{k} t+i k r_{B}\right) / r_{B}
\end{aligned}
$$




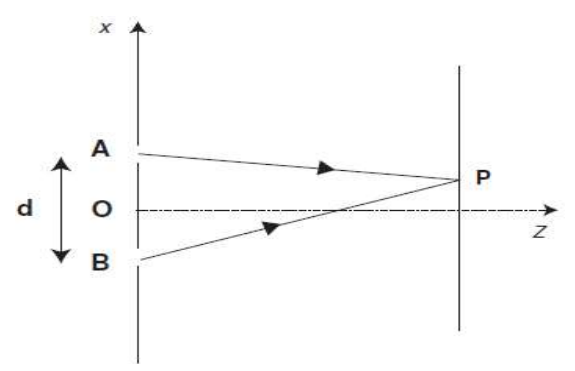

Figure 1. Schematic design of Young's double slit experiment (Yabuki, H, 1986)

where $r=(x, y, z)$ denotes the observation point on the screen and $\mathrm{r}_{\mathrm{A}}, \mathrm{r}_{\mathrm{B}}$ the distance between each slit and the observation point :

$$
r_{A}=\sqrt{(x-d / 2)^{2}+y^{2}+z^{2}}, r_{A}=\sqrt{(x+d / 2)^{2}+y^{2}+z^{2}}
$$

the wave number and frequency are denoted $k=\left(k_{x}, k_{y}, k_{z}\right)$ with $k=|\boldsymbol{k}|$ and $\omega_{k}$. Amplitudes expand of absolute values and phases for double-sources : $A_{0}=\left|A_{0}\right| \exp \left(i \theta_{A}\right), B_{0}=\left|B_{0}\right| \exp \left(i \theta_{B}\right)$. Intensity of wave function is given as

$$
\left|F_{k}^{D S}(r, t)\right|^{2}=\left|F_{k}^{A}(r, t)\right|^{2}+\left|F_{k}^{B}(r, t)\right|^{2}+2 \operatorname{Re}\left(F_{k}^{A}(r, t)^{*} F_{k}^{B}(r, t)\right)
$$

where the interference effect appears in the last term as

$$
\begin{aligned}
2 \operatorname{Re}\left(F_{k}^{A}(r, t)^{*} F_{k}^{B}(r, t)\right) & =2 \frac{\left|A_{0}\right|\left|B_{0}\right|}{r_{A} r_{B}} \cos \left(k\left(r_{A}-r_{B}\right)+\theta_{A}-\theta_{B}\right) \\
& \cong 2 \frac{\left|A_{0}\right|\left|B_{0}\right|}{r^{2}} \cos \left(-k x d / r+\theta_{A}-\theta_{B}\right)
\end{aligned}
$$

Which holds on $d<<r=\sqrt{x^{2}+y^{2}+z^{2}}$. The intensity is interpreted as the probability density.

Therefore basically cased here is what happen if the experiments use multiple-slit, is there a limit how many probabilities appears of each slits as a interference pattern results through on the screen. In order to fathom that cases, it is hold on an approximation Feynman path integral formula (Kenmoku and Kume, 2011).

Feynman path integral method is a functional integral, which holds phase factor on functional trajectory between initial and final position. The path integral had given a representation of field as an alternatif of conventional method at past. Simply out from that problem is whether advantages or not between both methods, path integral and canonic in order to fix that case of the field theory, thus this research exhibits the role play of path integral method for various quantum mechanics system and scalar fields which are continued making the patterns (Latifah, 2011).

\section{Research Analysis}

In the early quantum history is regarded to basic concepts, which holds on propagating emitted particle, electron. The emitted particle experiment set is given by (figure 2)

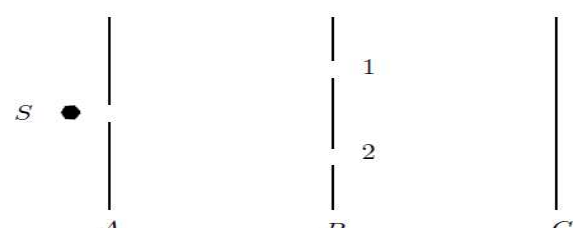

Figure 2. Emitted particle experiment set (Yabuki, H, 1986) 
Before the emitted particles expand the detector at $\mathrm{x}$ which flows through on the vertical screen $\mathrm{C}$ (figure 2.1), particles had flown at both slits with this assumption as:

1. If the slit 2 (bottom) is closed, particle flows through slit 1 (top) only, then the particle distribution is faced to detector on the screen $\mathrm{C}, \mathrm{P}_{1}$, as fixed (figure 2.a)

2. If the slit 1 is closed, then the path of particle is through the slit 2 (bottom), therefore the particle distribution on the screen $\mathrm{C}, \mathrm{P}_{2}$, is given by (figure 2.b)

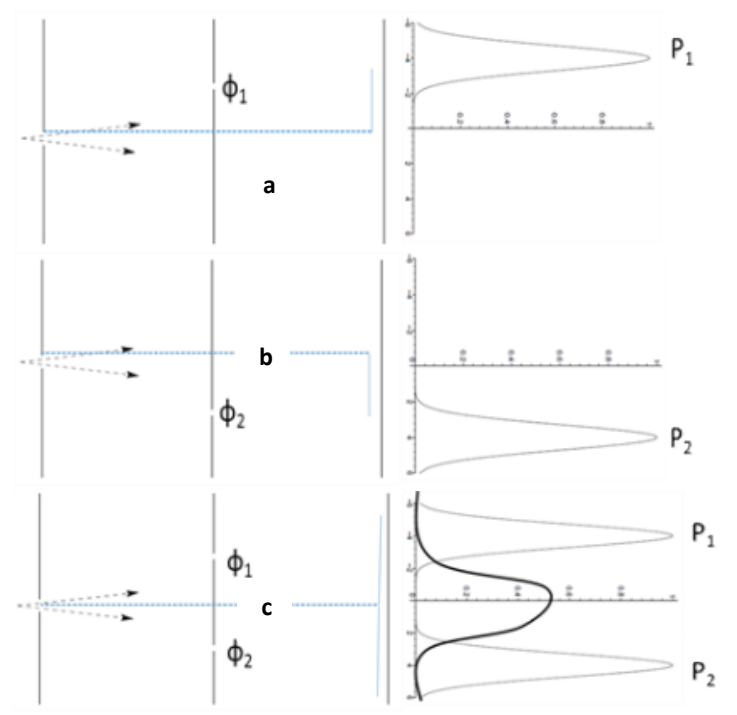

Figure 2. Schema emitted particle macroscopically (Beau, M, 2012)

As statement before, it is assumed that if slit 1 and slit 2 are opened then the particle distribution on the screen $\mathrm{C}$ has the sum of $\mathrm{P}=\mathrm{P}_{1}+\mathrm{P}_{2}$ and shapes a curve as given by (figure 2.c). However, the fact as experimentally look is not stated. But there is fluctuation as stated (figure 3). This phenomena shows that the particle trajectory from $\mathrm{S}$ to the detector has alternative paths as stated by (figure 3 ), even such as propagate zig-zag between the screen $\mathrm{A}$ and $\mathrm{B}$ before expanding the screen $\mathrm{C}$. These paths are increasing Feynman's intuition.
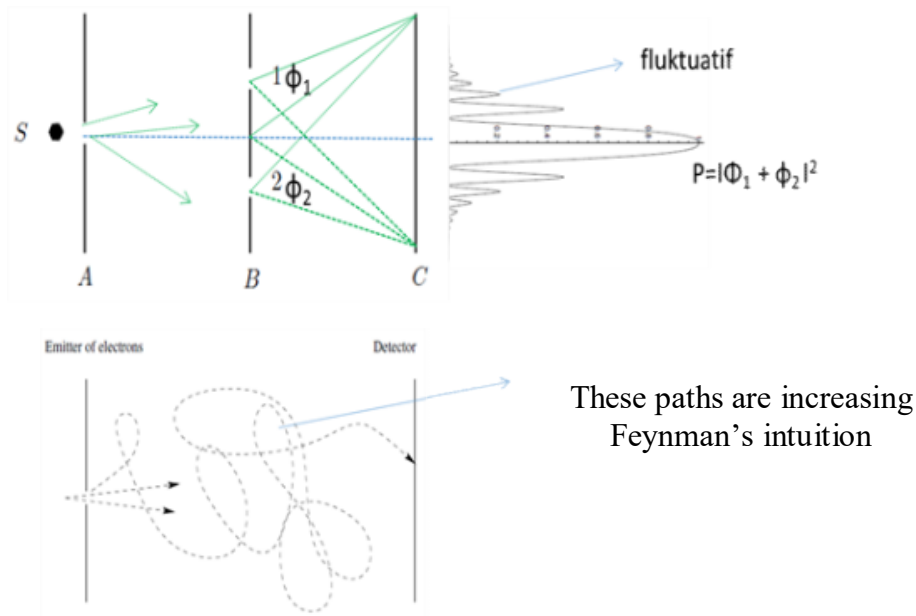

Figure 3. Schema fluctuative and paths with approximation path integral (Yabuki, H, 1986) 


\subsection{Intuitive Approximation to the Path Integral Formalism}

In the double-slit experiment, we get two alternatives of interference for the path of electrons from A to $\mathrm{C}$. The idea behind the path integral approach to quantum mechanics is to take the implications of the double-slit experiment to its extra-ordinary consequences. One could imagine that if we add many screens and dropped more and more holes through them, then the commonly result of the double-slit experiment is fixed by the superposition principle. This is the procedure illustrated by Feynman in his book "Quantum Mechanics and Path Integrals".

\section{Schematically:}

1. With two slits : we know that $\Phi=\Phi_{1}+\Phi_{2}$

2. If we open $\mathrm{n}$ slits, the superposition principles still applies $\Phi=\Phi_{1}+\Phi_{2}+\Phi_{3}+\cdots+\Phi_{n}$ (multiple slits)

3. Imagine, adding an intermediate screen $\mathrm{D}$ with $\mathrm{N}$ holes at positions $x_{D}^{1}, x_{D}^{2}, \ldots, x_{D}^{N}$ (see figure 2.4). The possible trajectory are now denoted $x_{D}^{i}$ and $\alpha=1,2,3$.

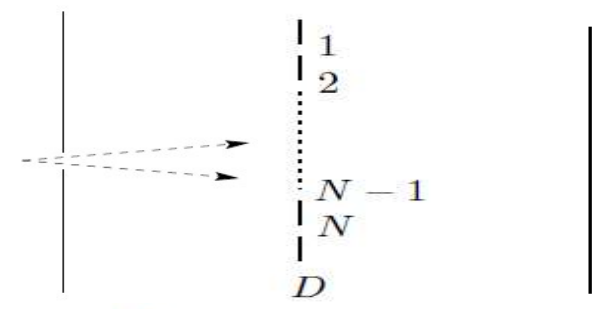

Figure 4. Emitted particle experiment set with N slits (Yabuki, H, 1986)

Applying the superposition principle

$$
\Phi=\sum_{i=1}^{N} \sum_{\alpha=1,2,3} \Phi\left(x_{D}^{i}, \alpha\right)
$$

Taking the limit where $N \rightarrow \infty$ and the holes fill all of D. The sum $\sum_{i}$ becomes now an integral over $x_{D}$.

$$
\Phi=\sum_{\alpha=1,2,3} \int_{D} d x_{D} \Phi\left(x_{D}, \alpha\right)
$$

Then the trajectories by adding many screens $D_{1}, D_{2}, \ldots, D_{M}$

$$
\Phi=\sum_{\alpha=1,2,3} \int_{D_{1}} d x_{D_{2}} \ldots d x_{D_{M}} \Phi\left(x_{D_{1}}, x_{D_{2}}, \ldots, x_{D_{M}} ; \alpha\right)
$$

In the limit $D_{i}, D_{i+1}$ become closely infinite, we had specified possible paths $x(y)$ (see figure 5 for a schematic representation, where the screen $B$ has been dropped in order to assume the simpler case of propagation in empty space). 


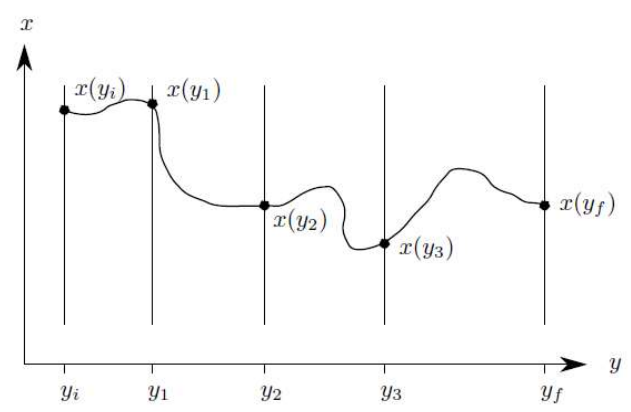

Figure 5. Schema the path $\mathrm{x}(\mathrm{y})$ as possible of elektrons propagation (Marchella, 2007)

Then get a formal representation of the probability amplitude as a sum over trajectories as possible:

$$
\Phi=\sum_{\text {all trajectories }\{x(t), y\{t\}\}} \Phi(x)
$$

How is this formula made sense of? How is it normalized? Now we could make a good spesification of particle motion. It is not only analyze a part of the path, but analyze the initial and final time of space before expanding to the detector. The path is given as two-dimensional with two function $x(t), y(t)$ then we had an idea in order to take its amplitude from that path $x(t), y(t)$. The total amplitude which arrives at the detector is the sum or integral of amplitude from over the possible path. Defining this concept of the sum or integral over the path mathematically with more precision way explaining next.

\subsection{Amplitude in Quantum Mechanics}

Had noted that the existence of amplitude each trajectories are based on the initial position $x_{i}$ at the initial time $t_{i}$ and the final position $x_{f}$ at the final time $t_{f}$. If a particle an an initial time starts from the initial point and towards to a final point at the final time, we could say simply that the particle goes from A to B and the function $x(t)$ is denoted $x\left(t_{a}\right)=x_{a}$ and $x\left(t_{b}\right)=x_{b}$. In quantum mechanics, the contribution of over all amplitude is contribution of each paths with action $\mathrm{S}$ to the path per unit $\hbar$. Thus the probability $P(b, a)$ moves from $x_{a}$ point at the time $t_{a}$ to $x_{b}$ point at the time $t_{b}$ is the absolut square of amplitude $K(b, a), P(b, a)=|K(b, a)|^{2}$. This amplitude is the sum of contribution $\phi[x(t)]$ of each paths[7-9].

$$
K(b, a)=\sum_{\text {overall paths from a to } b} \phi[x(t)]
$$

and each paths have

$$
\phi[x(t)]=\text { const } e^{(i / \hbar) S[x(t)]}
$$

where clasically action term as

$$
S[x(t)]=\int_{t_{a}}^{t_{b}} L(\dot{x}, x, t) d t
$$

\section{Calculation For The Type of Path Composition}

Beginning at assumption in two-dimensional space with the coordinate is given by (figure 5). The System Lagrangian as

$$
L=\frac{m}{2}\left(\dot{x}^{2}+\dot{y}^{2}\right)-V(x, y)
$$


where

$$
V(x, y)=\begin{aligned}
& V \quad \text { for } 0 \leq x \leq \delta ; y \leq-\frac{\lambda}{2}-\varepsilon,-\frac{\lambda}{2} \leq y \leq \frac{\lambda}{2}, \frac{\lambda}{2}+\varepsilon \leq y \\
& \quad \text { in line area of the figure below) } \\
& 0 \quad \begin{array}{l}
\text { otherwise }
\end{array}
\end{aligned}
$$

Directly at approximation Feynman path integral method. In this case, a particle moves freely except on the screen. Calculation of free propagator as

being $S[b, a]$ free action

$$
\begin{aligned}
& K(b, a)=\int_{a}^{b}[D x] \exp \frac{i}{\hbar} S[b, a] \\
& S[b, a]=\int_{t_{a}}^{t_{b}} \frac{m}{2}\left\{\dot{x}(t)^{2}+\dot{y}(t)^{2}\right\} d t
\end{aligned}
$$

label of $[D x]$ is measure path integral, and $a=\left(t_{a}, A\right)=\left(t_{a} ; x_{a}, y_{a}\right)$, etc . Explisitly (Feynman and Hibbs, 1965)

$$
K(b, a)=\left[\frac{2 \pi i \hbar\left(t_{b}-t_{a}\right)}{m}\right]^{-1} \exp \frac{i m\left\{\left(x_{b}-x_{a}\right)^{2}+\left(y_{b}-y_{a}\right)^{2}\right\}}{2 \hbar\left(t_{b}-t_{a}\right)}
$$

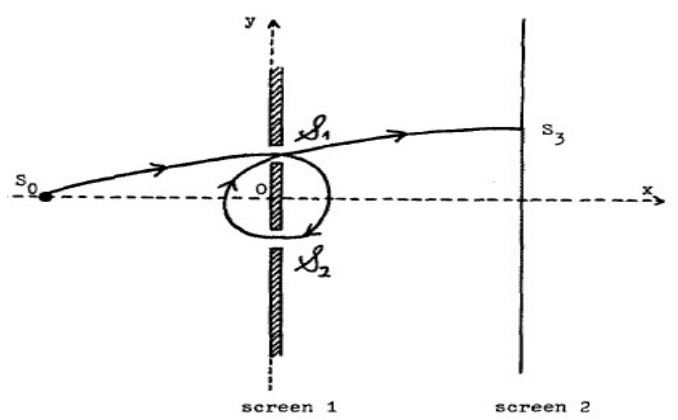

Figure 6. Eksperiment set with the path of electron randomly (Beau, M, 2012)

Based on assumption of contribution that path is given by (figure 6), it is necessary to compute amplitude transition to path composition. For this goal, we use the identity as

$$
K(b, a)=\int K(b, c) K(c, a) d x_{c} d y_{c}
$$

being $t_{c}$ interval as

substituting trivial equality

$$
t_{b}>t_{c}>t_{a}
$$

$$
\frac{1}{t_{b}-t_{a}}=\int_{t_{a}}^{t_{b}} d t_{c}
$$

then substitute from eq. (3.6), is obtained

$$
K(b, a)=\frac{1}{t_{b}-t_{a}} \int_{t_{a}}^{t_{b}} d t_{c} \int d x_{c} d y_{c} K(b, c) K(c, a)
$$

We are interested in calculation of contribution from this path where a particle moves from A to B by small area $\rho$ (figure 3.2), and it is obtained the relation amplitude transition with space integral for domain $\rho$ :

$$
K(b, a)_{\rho}=\frac{1}{t_{b}-t_{a}} \int_{t_{a}}^{t_{b}} d t_{c} \int_{x_{c}, y_{c} \in \rho} d x_{c} d y_{c} K(b, c) K(c, a)
$$



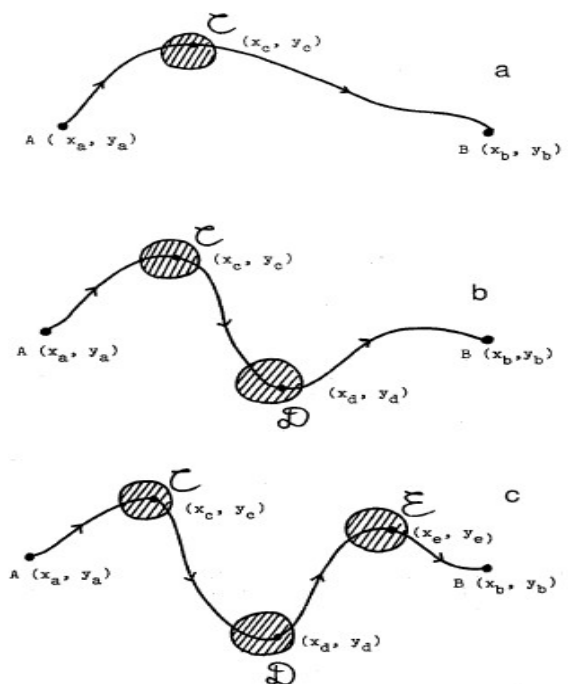

Figure 7. Combination of path (Mc. Kay, 2001)

Changing integration term, integral over $t_{c}$ is assumed ;

$$
\begin{aligned}
I_{1} & =\frac{1}{t_{b}-t_{a}} \int d t_{c} K(b, c) K(c, a) \\
& \approx\left(\frac{2 \pi i \hbar}{m}\right)^{-3 / 2}\left(t_{b}-t_{a}\right)^{-3 / 2} l_{b c}^{-1 / 2} l_{c a}^{-1 / 2} \exp \left[i \frac{m\left(l_{b c}+l_{c a}\right)^{2}}{2 \hbar\left(t_{b}-t_{a}\right)}\right]
\end{aligned}
$$

where

$$
l_{b c}=\left[\left(x_{b}-x_{c}\right)^{2}+\left(y_{b}-y_{c}\right)^{2}\right]^{1 / 2}
$$

and

$$
l_{c a}=\left[\left(x_{c}-x_{a}\right)^{2}+\left(y_{c}-y_{a}\right)^{2}\right]^{1 / 2}
$$

If it is assumed area $\rho$ small then the right term at eq.(3.8) could be written as

$$
K(b, a)_{\rho} \approx|\rho| \cdot I_{1}
$$

where $|\rho|$ is area from domain $\rho$. The relation with the method of eq.(3.7) is valid. In the same way, it will be obtained as amplitude transition for (figure 3.2.b and 3.2.c)[10-12]:

$$
\begin{aligned}
K(b, a) & =\frac{1}{t_{b}-t_{a}} \int d t_{d} \int d x_{d} d y_{d} K(b, d) K(d, a)_{\rho} \\
& \approx\left(\frac{2 \pi i \hbar}{m}\right)^{-2}|\rho \| D|\left(t_{b}-t_{a}\right)^{-2} l_{b d}^{-1 / 2} l_{d c}^{-1 / 2} l_{c a}^{-1 / 2} \\
& \times\left(l_{b d}+l_{d c}+l_{c a}\right)^{-1 / 2} \exp \left[i \frac{m\left(l_{b d}+l_{d c}+l_{c a}\right)^{2}}{2 \hbar\left(t_{b}-t_{a}\right)}\right] \\
K(b, a)_{\rho D \rho} & =\frac{1}{t_{b}-t_{a}} \int_{t_{a}}^{t_{b}} d t_{e} \int_{\left(x_{e}, y_{e}\right) \in \rho} d x_{e} d y_{e} K(b, e) K(e, a)_{D \rho}
\end{aligned}
$$




$$
\begin{aligned}
& \approx\left(\frac{2 \pi i \hbar}{m}\right)^{-5 / 2}|\rho\|D\| \rho|\left(t_{b}-t_{a}\right)^{-5 / 2} l_{b e}^{-1 / 2} l_{e d}^{-1 / 2} l_{d c}^{-1 / 2} l_{c a}^{-1 / 2} \\
& \times\left(l_{b e}+l_{e d}+l_{d c}+l_{c a}\right)^{-1} \exp \left[i \frac{m\left(l_{b e}+l_{e d}+l_{d c}+l_{c a}\right)^{2}}{2 \hbar\left(t_{b}-t_{a}\right)}\right]
\end{aligned}
$$

\section{Conclusion}

One of the best examples of the practical lab such as seen in the quantum world is the double-slit experiment. Taking a piece of material, blocks and cut two small slits in it, hit the slits with photons/ electrons, and they will interferen with each other, shows a pattern of peaks and valleys where the wavelengths of the photons interfered constructively and destructively intake. In many cases, it will also work as a probability when it is faced to with the double slit.

This concept which has pretty explained because the path of particle as a grapher of interference pattern however it also raises a question: what happens if there's more than two slits? Is there a limit how many probabilities a single particle can include at A paper will be released by "Science" today that provides a pretty clear answer (John Timmer, July 23, 2010).

That topic which inadvertents by writer is about the double-slit interference with the Feynman path integral approximation. For next research, writer do explaining that topic is multiple-slit in Feynman path integral. And is also inadvertent, because the expansion of research that I analyse factly still studied by researchers till now, thus I chalenged to try expand this research, because it is not got data yet, both derivation in detail and its simulation in forming the pattern from the multiple-slit interference result.

\section{Reference}

A.Campo de, “An Introductory Lecture on Feynman Path Integral.” 16-Jul-2004.

B. Mckay, "Path Integrals in Quantum Mechanics." 19-Nov-2001.

C. Egli, "Feynman Path Integrals in Quantum Mechanics." 01-Oct-2004.

E. Latifah, "Integral Lintas Feynman dalam Efek Casimir," ITS Surabaya.

H. Sanabria and B. . Rodriguez-Lara, "An Introduction to Quantum Interferometry: Young's Experiment with Fock and Coherent States,” vol. E 53(1), pp. 1-9, Jun. 2007.

H. Yabuki, "Feynman Path Integrals in the Young Double-Slit Experiment," pp. 1-16, Sep. 1986.

K. Schulten, Notes on Quantum Mechanics. 2000.

M. Beau, "Feynman Integral and one/two slits electrons diffraction : an analytic study," pp. 1-24, Mar. 2012.

M. Kenmoku and K. Kume, "Young's Double Slit Experiment in Quantum Field Theory," pp. 1-11, Mar. 2011.

R. Rattazzi, The Path Integral approach to Quantum Mechanics Lecture Notes for Quantum Mechanics IV. 2009.

R. Schuster, "On the Role of Quantum Events in Double Slit Experiment," pp. 1-13, Apr. 2011.

T. Marcella V, "Quantum Interference with Slits.”, 2007. 